\title{
Surface Analysis of AISI 410 Stainless Steel Cladding with AlN, Si, Co, and W Powders
}

\author{
Tzung-Ming Chen* and Hsin-Min Lee ${ }^{1}$ \\ Department of Industrial Education and Technology, National Changhua University of Education, \\ No. 2, Shida Road, Changhua, Taiwan \\ ${ }^{1}$ Department of Mechanical Engineering, Army Academy of the ROC, No. 750, Longdong Rd., Zhongli, Taiwan
}

(Received December 25, 2015; accepted June 6, 2016)

Keywords: GTAW, cladding, AIN, heat dissipation, wear resistance

In this study, the surface modification of AISI 410 stainless steel with an AlN clad layer was investigated. For the purpose of improving the uniformity and combining ability of the clad layer, specific amounts of elemental $\mathrm{Si}, \mathrm{W}$, and Co were added. The gas tungsten arc welding method was used for the cladding procedure. The analysis was focused on the success of the cladding procedure and the modification effect of the clad layer. To meet the demand mentioned, electron probe microanalysis was used to detect the chemical composition, and scanning electron microscopy was used to observe surface wear. Furthermore, hardness and wear tests were used to verify the mechanical properties, and temperature measurement was used to ensure the heat dissipation. The experimental results show that the surface hardness, wear resistance, and heat dissipation of cladding AISI 410 were better than naked AISI 410.

\section{Introduction}

The objective of this research was to modify the surface properties of AISI 410 stainless steel by gas tungsten arc welding (GTAW). AISI 410 is a martensitic-type stainless steel, which is quite prevalent in industry because of its excellent properties. For example, high hardness and stiffness, high thermal conductivity, low thermal expansion, good wear resistance, and good corrosion resistance. ${ }^{(1)}$ One application of AISI 410 is in the disc brakes of vehicles. ${ }^{(2)}$ Even though the reliability of stainless steel is good, during the braking period, the contact surface between the disc and lining gradually decays. To overcome this shortcoming, a layer of AlN and some additional specific elements is cladded on AISI 410 to modify the metallurgical behavior of the contact surface during braking.

AlN is chosen as the main component of the cladding layer because of its high thermal conductivity and low thermal expansion. AlN is a technical ceramic and is widely used in photoelectrics because of its good thermal shock resistance. ${ }^{(3)}$ In addition, AlN can be used to decrease oxidation between the two surfaces during wear. ${ }^{(4)}$ Its traditional application is as a heat sink or power transistor base, for example, in device packages, chamber fixtures, or handling components. ${ }^{(5)}$ Based on these successful applications, it is worthwhile to evaluate the feasibility of extending its application to automotive industries.

"Corresponding author: e-mail: tmchen@cc.ncue.edu.tw 
There are many methods of cladding. GTAW is a molten or semi-molten method. ${ }^{(6,7)}$ The main advantages of GTAW are low cost and high workability. During the cladding process, the arc induces high temperature, and it melts or partially melts the cladding materials with the base material on the working surface. When the molten region cools to the solid state, the cladding layer combines with the base material, and the mechanical properties of the working surface are improved in terms of higher hardness, stronger wear resistance, and faster heat dissipation, because the contribution to the properties is not only from the base material but also from the cladding materials. Therefore, it is useful to analyze the microstructure of the molten region to verify the improvement in properties.

The welding between stainless steel and AlN is heterogeneous. The uniformity of the molten region and the ability of the base material to combine with the cladding layer are the main concerns during the cladding procedure. Yagati et al., in the study of fluxless arc weld-brazing, stated that the intermetallic compound is one of strengthening mechanisms in grain boundaries. ${ }^{(8)}$ Coelho et $a l$. , in the study of friction-stir dissimilar welding, stated the possibility of combining aluminum alloy and steel. Moreover, the hardness of the welding is enhanced by the uniformity of the molten region. ${ }^{(9)}$ Dong et al. reported the effect of dissimilar metal joints between aluminum alloy and stainless steel using GTAW. The time and temperature of heat treatment influenced the combined strength. ${ }^{(10)}$ Wang et al. in 2003 reported that the wear resistance of the surface of AISI 1050 could be enhanced by specific elements. ${ }^{(1)}$ Our research extends this discussion to the contribution of specific elements, based on the combining stability of heterogeneous welding in the GTAW method.

Three elements, $\mathrm{Si}, \mathrm{W}$, and Co, were added to AlN to improve the combination stability of welding. Elemental $\mathrm{Si}$ and $\mathrm{W}$ are predicted to remain stable in the metal and form $\mathrm{SiC}$ or WC, resulting in improved wear resistance. The wear resistance of stainless steel can be reinforced by SiC. . $^{(12)}$ The hardness and wear resistance of WC are both excellent. Hence, WC is well used in cutting tools. ${ }^{(13)}$ Co is predicted to be an adhesive for $\mathrm{W}$ and maintains the stiffness and stability of a working surface after the cladding procedure. ${ }^{(14)}$

\section{Experiments}

\subsection{Specimen preparation}

The dimension of the welding specimen was $50 \times 15 \times 9.5 \mathrm{~mm}^{3}$, and a shallow slot was fabricated on the top surface of the specimen, as shown in Fig. 1. The oxide layer was removed during milling, and then the prepared base material, AISI 410, was cleaned in an ultrasonic cleaning tank before welding.
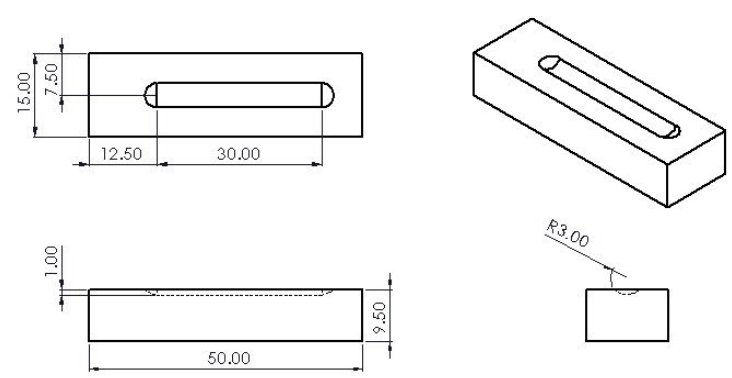

Fig. 1. Dimensions of the specimen (mm). 


\subsection{Powder mixing}

Four different powders, AlN, Si, W, and Co were included in the clad layer. Each component was weighed and placed in a bottle. Finally, to obtain uniformity, the collected powders were mixed in a planetary ball mill for $2 \mathrm{~h}$ with a constant rotational speed of $250 \mathrm{rpm}$.

\subsection{Cladding}

The mixed powder was spread in the shallow slot of the specimen and baked in an oven at 60 ${ }^{\circ} \mathrm{C}$ for $24 \mathrm{~h}$. The cladding proceeded only when the moisture was removed from the pre-coated powder. The feeding speed and the current of welding were set at $1 \mathrm{~cm} / \mathrm{min}$ and $60 \mathrm{~A}$. To obtain a smooth and stable weld, a one-axis automatic feed mechanism was used. To evaluate the effects of specific elements, three kinds of specimens, SP1, SP2, and SP3, were prepared with different compositions (see Table 1). The welded specimen was then air cooled until it returned to room temperature.

\subsection{Machining}

After cladding, the lateral section of the welding specimen was cut out using a wire-cutting machine for the hardness test, surface observation, and the analysis of chemical composition. In addition, a specimen with a curved tip was machined for the wear test and temperature measurement. The shape and dimension are shown in Fig. 2.

\section{Results and Discussion}

\subsection{Compositional analysis}

Electron probe microanalysis (EPMA) was used for molten regions. The status of the 7 key compositional elements - $\mathrm{Fe}, \mathrm{Cr}, \mathrm{Al}, \mathrm{Co}, \mathrm{Si}, \mathrm{W}$, and $\mathrm{N}$ - that were present in $\mathrm{SP} 1$ are shown in Figs. 3 and 4 . The mapping diagrams show that the mixed powder was uniformly dispersed in the molten region. Similar results for SP2 and SP3 are shown in Figs. 5-8. The analytical results confirm that GTAW method was successful.

Table 1

Specimen compositions (wt.\%).

\begin{tabular}{lllll}
\hline & AlN & Si & W & Co \\
\hline SP1 & 95 & 1.75 & 2.50 & 0.75 \\
SP2 & 95.5 & 2.50 & 1.25 & 0.75 \\
SP3 & 96 & 1.25 & 1.75 & 1.0 \\
\hline
\end{tabular}
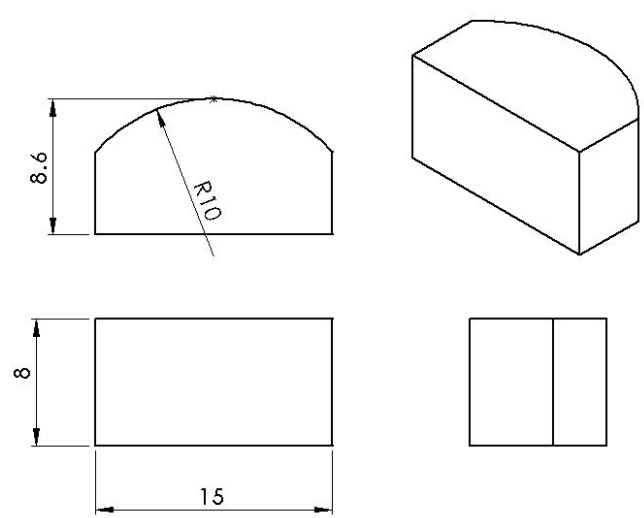

Fig. 2. The shape and dimensions of the wear specimen $(\mathrm{mm})$. 


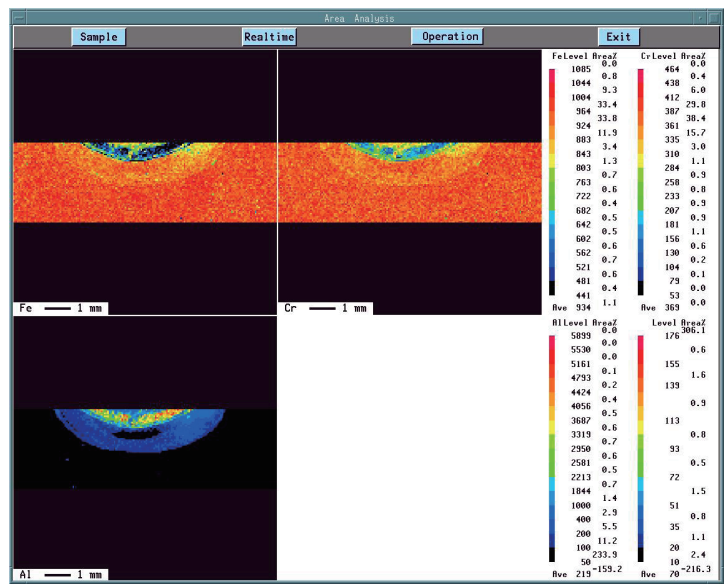

Fig. 3. (Color online) Detection of $\mathrm{Fe}, \mathrm{Cr}$, and $\mathrm{Al}$ on SP1 by EPMA.

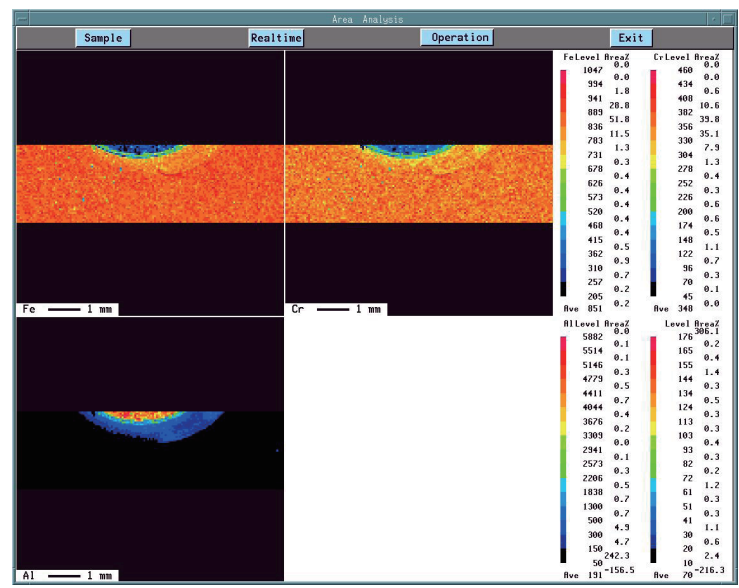

Fig. 5. (Color online) Detection of $\mathrm{Fe}, \mathrm{Cr}$, and $\mathrm{Al}$ on SP2 by EPMA.

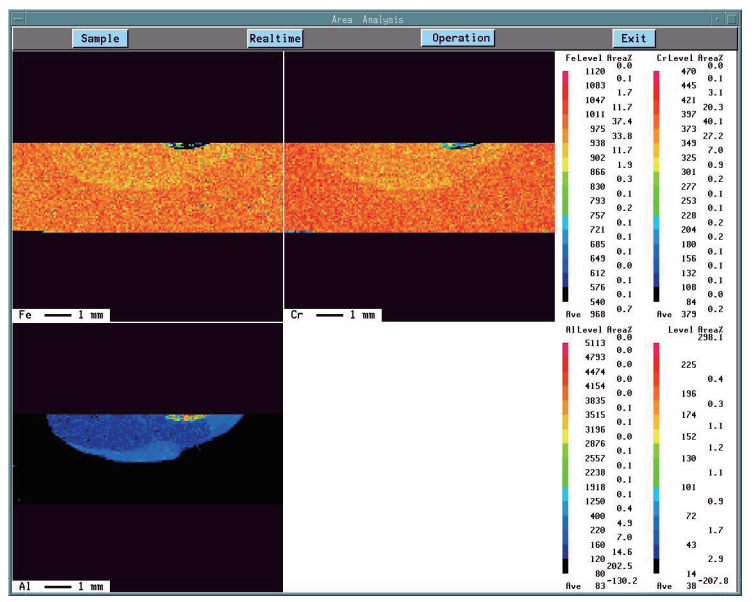

Fig. 7. (Color online) Detection of $\mathrm{Fe}, \mathrm{Cr}$, and $\mathrm{Al}$ on SP3 by EPMA.

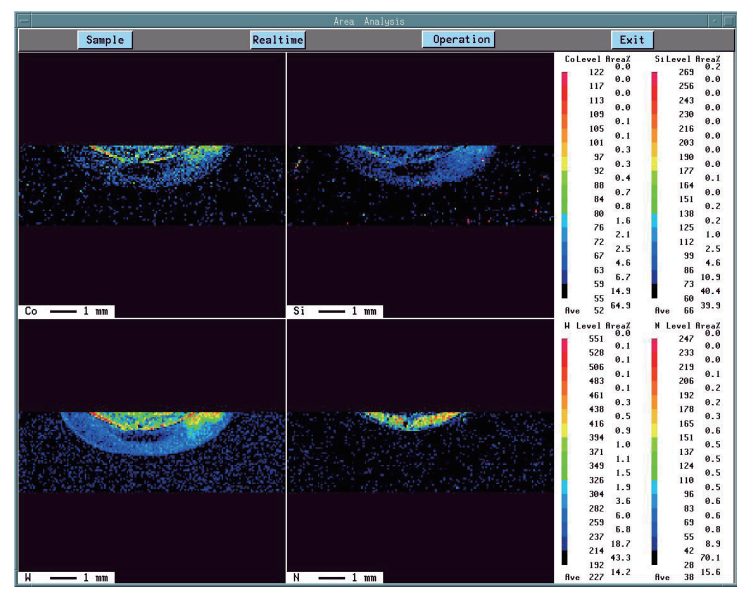

Fig. 4. (Color online) Detection of $\mathrm{Co}, \mathrm{Si}, \mathrm{W}$, and $\mathrm{N}$ on SP1 by EPMA.

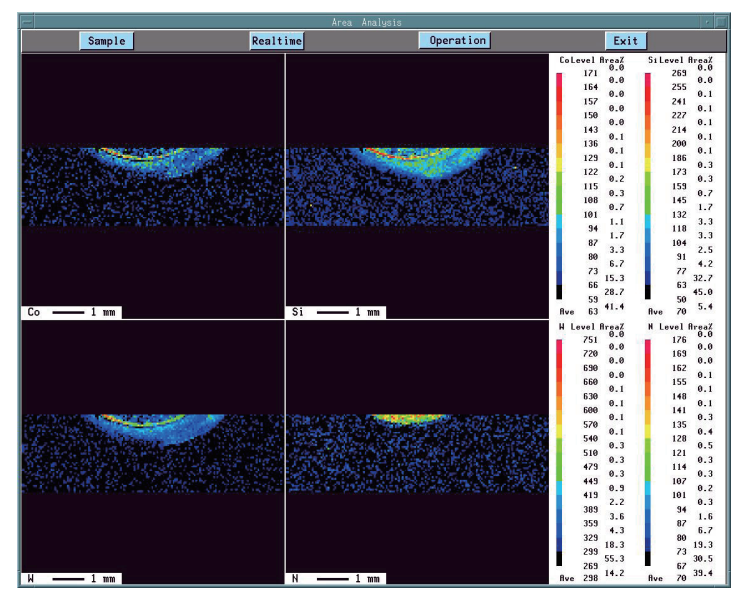

Fig. 6. (Color online) Detection of $\mathrm{Co}, \mathrm{Si}, \mathrm{W}$, and $\mathrm{N}$ on SP2 by EPMA.

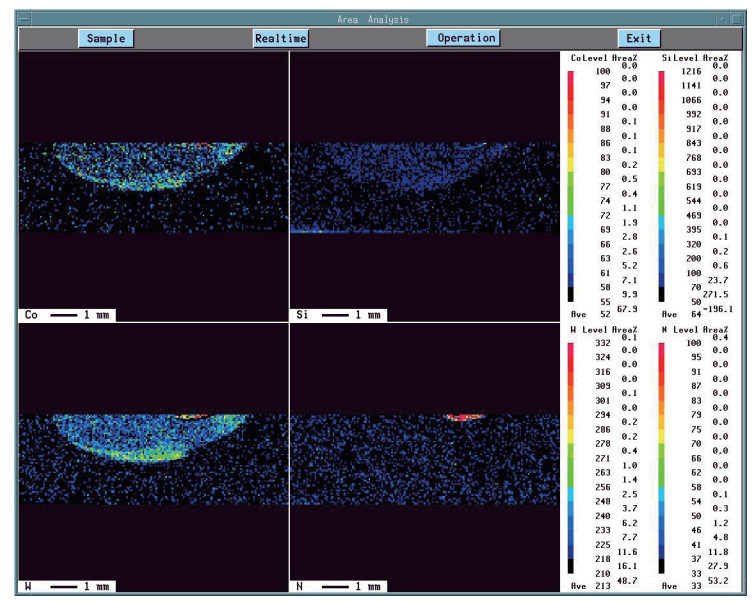

Fig. 8. (Color online) Detection of $\mathrm{Co}, \mathrm{Si}, \mathrm{W}$, and $\mathrm{N}$ on SP3 by EPMA. 


\subsection{Hardness}

In this study, the hardness was measured in three regions. The molten region, the heat-affected zone, and the base material. The surface hardness of naked AISI 410 without any oxide layer, which is between HRB 80 and HRB 84, was taken as the reference. The comparison of the three specimens and naked AISI 410 is shown in Figs. 9-11. It is clear that the heat-affected zone and the base material of SP1, SP2, and SP3 were much harder than naked AISI 410. This behavior arises because martensitic transformation occurs during air cooling. ${ }^{(15)}$ The value ranged from HRB 91 to HRB 98. With a harder base, the clad layer demonstrated firm contact behavior. If a hard surface or hardened thin film was cladded on a soft base, the surface could be easily cracked when it was loaded. Another noteworthy matter is that the hardness of the SP3 in three regions was nearly the same. On the other hand, the hardness of the molten region of the three specimens was comparable to the hardness of naked AISI 410 (See Fig. 12). The hardness of the molten region of SP3 was HRB 91-95, which was the hardest among the three specimens. In contrast, the softest was SP2, with a hardness of HRB 86-88. This result implies that the amount of W did not directly contribute to the hardness of the molten region.

The amount of Co played an important role in combination with $\mathrm{W}$ during the melting process. Another analytical result of comparing SP2 and SP3 showed that the contribution of Si in AISI 410 was less than that of $\mathrm{W}$.

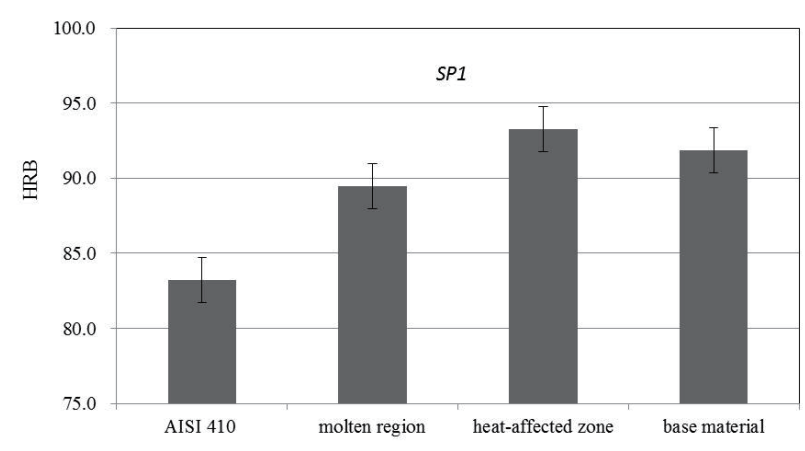

Fig. 9. The hardness distribution of SP1.

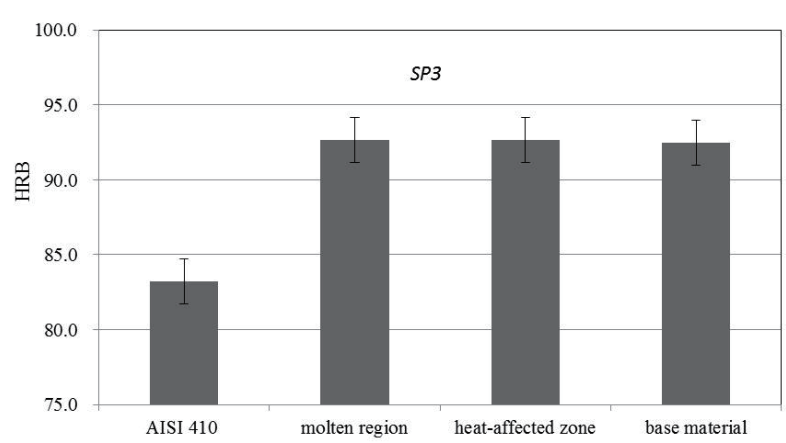

Fig. 11. The hardness distribution of SP3.

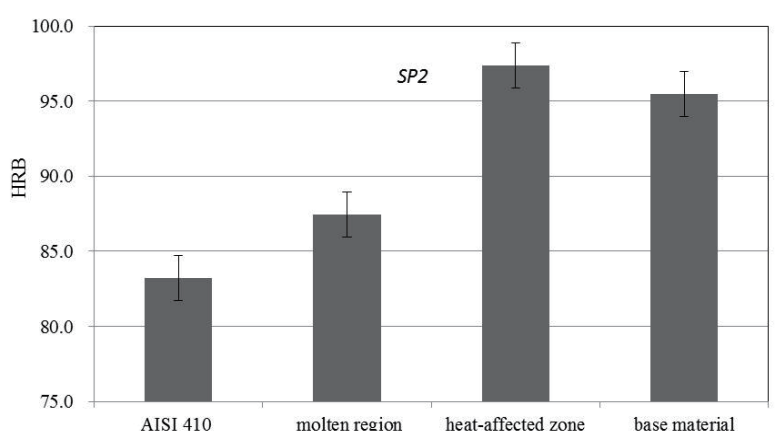

Fig. 10. The hardness distribution of SP2.

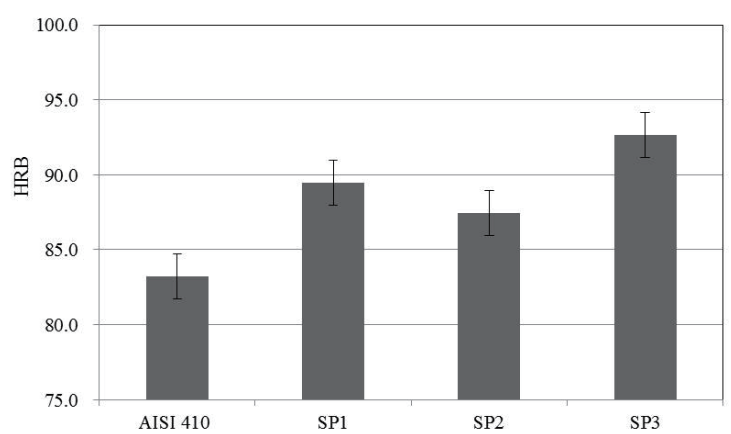

Fig. 12. The hardness of the molten region of three specimens compared with AISI 410. 


\subsection{Wear resistance}

A pin-on-disc wear test was used in our study, in which the specimen was placed on the pin side and the counterpart, a commercially available semi-metal brake lining, was placed on the disc side. During the test, a constant contact load of $17 \mathrm{~N}$ and a relative moving speed of $12.72 \mathrm{~km} / \mathrm{h}$ were maintained for $30 \mathrm{~min}$. The loss volume due to wear of the three specimens and naked AISI 410 are shown in Fig. 13. The loss volume due to wear of AISI 410 is $1.47 \mathrm{~mm}^{3}$; and for SP1, SP2, and SP3, 0.88 , 0.92 , and $0.85 \mathrm{~mm}^{3}$, respectively. It is obvious that the clad layer improved wear resistance, which implies that the base material is strengthened by AlN. Furthermore, SP3, with a sufficient amount of Co, retained $\mathrm{W}$ in the molten region. This result is consistent with the hardness measurement.

\subsection{Heat dissipation}

During the wear test, a K-type thermometer was used to measure the temperature of the specimen. The measurement period included a $30 \mathrm{~min}$ wear test and $15 \mathrm{~min}$ of air cooling. The comparison of SP1 and naked AISI 410 is shown in Fig. 14. The first 15 min was the warming stage, during which the trends of the curves are similar. However, the temperature of naked AISI 410 was higher than that of SP1. The second thermostatic stage occured for the next $15 \mathrm{~min}$. The average temperature of SP1 $\left(158^{\circ} \mathrm{C}\right)$ was lower than that of naked AISI $410\left(180{ }^{\circ} \mathrm{C}\right)$. Air cooling was the final stage, in which the curves were nearly the same. The comparison curves of SP2 and SP3 with AISI 410 are shown in Figs. 15 and 16, respectively.

SP2 had a steeper warming trend in the first $5 \mathrm{~min}$, and then slowed down, as shown by the slope. Furthermore, it had the lowest thermostatic temperature of $150{ }^{\circ} \mathrm{C}$. The peeling contributed to the removal of heat energy in the second and final stages, as is evident from the SEM images. The heat dissipation behavior of SP3 was similar to SP2 in the first stage. However, it was the worst among the three specimens in the second stage, in which the temperature was only a little lower than AISI 410 in the thermostatic stage. Even worse, the cooling trend of SP3 in the final stage was slightly slower than AISI 410. Investigating the relation between heat dissipation and worn surfaces of these three specimens, we found that the surface area was directly proportional to the dissipation ability. The reason for this behavior is that the hardest specimen, SP3, had the worst heat dissipation ability.

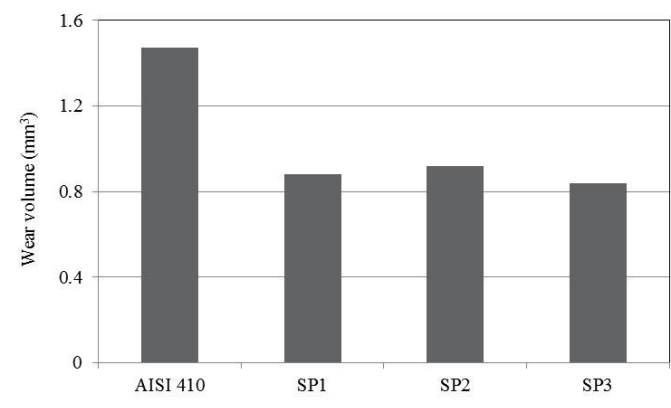

Fig. 13. Comparison of loss volume due to wear among SP1, SP2, SP3, and the naked AISI 410.

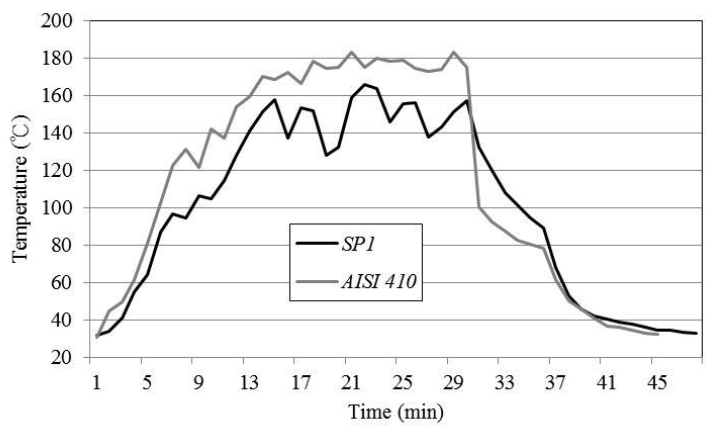

Fig. 14. Temperature comparison between SP1 and naked AISI 410. 


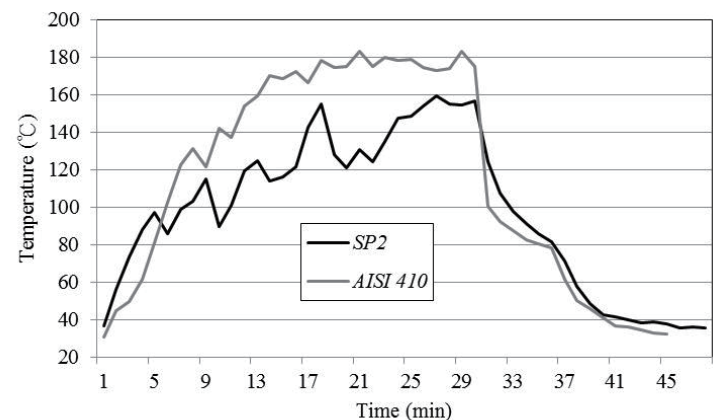

Fig. 15. Temperature comparison between SP2 and naked AISI 410.

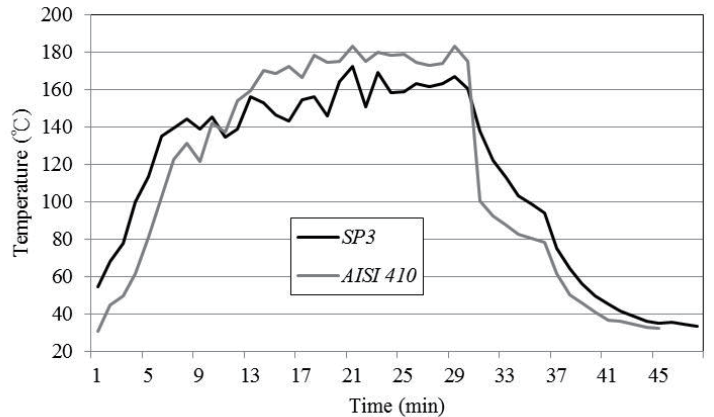

Fig 16. Temperature comparison between SP3 and naked AISI 410.

\section{Conclusion}

Based on the experimental results, the conclusions are generalized as follows:

- The cladding materials AlN, Si, W, and Co were uniformly dispersed in the molten region, as observed by EPMA, implying that the GTAW process is a feasible method for cladding AlN on AISI 410.

- The surface hardness of AISI 410 was improved by the AIN clad layer. The behavior of SP3 verifies that $\mathrm{W}$ exhibited a stable hardness only with a sufficient amount of Co.

- Because of the martensitic transformation, the heat-affected zone was harder than the surface. Based on this precondition, the wear volume has a direct relation to the surface hardness.

- The heat dissipation of AISI 410 was improved by the AlN clad layer. Moreover, the peeling phenomenon enhanced heat dissipation.

\section{References}

1 R. Puli and G. D. J. Ram: Surf. Coat. Technol. 209 (2012) 1.

2 K. A. G. Olabi, R. Lostado, and K. Y. Benyouni: Compr. Mater. Process. 6 (2014) 181.

3 A. A. Buchheit, G. E. Hilmas, W. G. Fahrenholtz, and D. M. Deason: J. Am. Ceram. Soc. 92 (2009) 1358.

4 Y. Birol and D. Isler: Wear 270 (2011) 281.

5 S. Yin, K. J. Tseng, and J. Zhao: Appl. Therm. Eng. 52 (2013) 120.

6 I. M. Hutchings: Tribology: Friction and Wear of Engineering Materials (Butterworth-Heinemann, Oxford, 1992) pp. 162-165.

7 K. Holmberg and A. Matthews: Coatings Tribology (Elsevier, Amsterdam, 1994) pp. 27-30.

8 K. P. Yagati, R. N. Bathe, K. V. Rajulapati, K. B. Sankara Rao, and G. Padmanabham: J. Mater. Process. Technol. 214 (2014) 2949.

9 R. S. Coelho, A. Kostka, J. F. dosSantos, and A. Kaysser-Pyzalla: Mater. Sci. Eng. A 556 (2012) 175.

10 H. Dong, C. Liao, L. Yang, and C. Dong: Mater. Sci. Eng. A 550 (2012) 423.

11 S. W. Wang, Y. C. Lin, and Y. Y. Tsai: J. Mater. Process. Technol. 140 (2003) 682.

12 S. Buytoz and M. Ulutan: Surf. Coat. Technol. 200 (2006) 3698.

13 T. Kagnaya, C. Boher, L. Lambert, M. Lazard, and T. Cutard: Wear 267 (2009) 890.

14 M. G. Fontana: Corrosion Engineering 3rd ed. (Mc-Graw Hill, Singapore, 1986) pp. 240-245.

15 Y. C. Lin and S. W. Wang: Tribol. Int. 36 (2003) 1. 